\title{
WHEN ARE LUNG RESECTIONS REALLY NECESSARY?
}

\author{
BY \\ WALTER LESH \\ From Abergele Chest Hospital
}

(RECEIVED FOR PUBLICATION MAY 13, 1961)

At a time when prolonged drug treatment is producing a diminishing number of patients with residual tuberculous lesions in need of surgery, it was thought that a review of the results obtained in a small thoracic surgical unit would be of interest. The series comprises some 200 resection operations by one surgeon; the first 100 patients in the series have been followed up. The review covers operations done during the years 1952-6, and it includes a mixed population whose ages varied from under 5 years to over 50 years. The hospital numbered 243 beds, which were allocated to 40 babies and infants, 33 boys and girls each in two age groups of 5 to 10 and 11 to 16 years respectively, and also 18 women and 53 men. All forms of treatment were available without preference for any special one. Most patients followed the sanatorium routine from the start, with the operation held in reserve only after prolonged medical treatment. The main bulk of the patients came from the industrial North, especially from the Manchester area. Change of environment formed the pillar of treatment; this cannot be stated with too much emphasis. The knowledge that surgical treatment is available in the remote countryside as well as in the heart of a big city often helps to increase a patient's confidence and willingness to be separated from his family for the time of his illness. It also assists in the recovery period as well as shortening the time of disablement from a period in hospital. Further, it is of value to a patient mentally not to have to change hospitals at the time of an operation.

Surgery can play only a limited role in the eradication of tuberculosis. It has been more widely practised since the discovery of streptomycin, which provides the umbrella for the various forms of surgical treatment, and the numerous publications of the past decade on the success of the various forms of thoracic surgery prove the value of drug treatment used in association. Bearing in mind this essentially medical approach to the problem of treatment, I cannot impress by large numbers. One hundred patients underwent lung resections and 90 of these were for pulmonary tuberculosis. During the same period of time some 1,300 patients passed through the sanatorium. Since 1956 this pace has altered very little, and the total number of lung resections is still less than 200 , namely, about 20 resections per annum. The year 1955 stands out with a peak of 35 operations, as pressure on beds was still heavy at that time. One more point of importance in the approach to treatment is the patient's own appreciation of his illness. Quite a few will press for discharge unless they are operated upon, as this is what impresses them most. Later on, when looking through the tables, it will be found that some of the operations could have been avoided, but this could not be foretold until the operation specimen was examined.

Age is an over-riding factor in deciding on an operation. Most resection operations were done in the age group of 11 to 25 years when the disease appears to be more progressive.

Table I shows that the age distribution does not vary much as the series proceeds in groups of 50 consecutive operations, no selection being made

TABLE I

AGE DISTRIBUTION

\begin{tabular}{c|c|c|c|c|c}
\hline $\begin{array}{c}\text { Age } \\
\text { (yr.) }\end{array}$ & Total & $\begin{array}{c}\text { First } \\
\text { Group } \\
(1-50)\end{array}$ & $\begin{array}{c}\text { Second } \\
\text { Group } \\
(51-100)\end{array}$ & $\begin{array}{c}\text { Third } \\
\text { Group } \\
(101-150)\end{array}$ & Total \\
\hline $0-5$ & 3 & 1 & 5 & 2 & \\
$6-10$ & 13 & 3 & 5 & 11 & 16 \\
$11-15$ & 33 & 12 & 10 & 3 & 53 \\
$16-20$ & 20 & 9 & 8 & 4 & 37 \\
$21-25$ & 19 & 8 & 5 & 2 & 16 \\
$26-30$ & 18 & 5 & 3 & 2 & 14 \\
$31-35$ & 8 & 3 & 4 & 2 & 14 \\
$36-40$ & 8 & 3 & 3 & 10 & 150 \\
$41-45$ & 9 & 4 & 4 & 50 & \\
$46-50$ & 5 & 2 & 1 & 50 & \\
$50+$ & 14 & 150 & 50 & 50 &
\end{tabular}

according to age. Under 5 years of age medical treatment was used as far as possible. Operative fitness depends to some extent on age. The younger age groups adapt better to the altered 
balance of the mechanical forces within the thorax following resection. Above the age of 40, with life expectation declining, compensatory mechanisms become increasingly difficult and there are more frequent complications. Corrective operations also depend on the age of the patient. Below the age of 10 most of the surgical loss will be replaced by later growth of the patient. Between the ages of 11 and 20 a phrenic crush will often be advisable. Above that age, when growth has ceased to come into play, corrective thoracoplasties may become necessary to prevent overdistension of the remaining lung and its complications.

One should not think lightly of the changes within the thorax following on the removal of more than three segments, though patients may feel and appear to be quite well fairly soon.

Second in importance to age is the history of the disease, with its periods of recession and relapse and its known duration (Table II).

TABLE II

LENGTH OF HISTORY IN CASES 1-100

\begin{tabular}{c|c|c|c}
\hline Age (yr.) & Weeks & Months & Years \\
\cline { 1 - 3 } $0-10$ & - & 2 & 7 \\
$11-20$ & 2 & 12 & 25 \\
$21-30$ & 2 & 6 & 17 \\
$31-40$ & 1 & 7 & 5 \\
$41-50$ & - & 2 & 9 \\
$50+$ & 5 & 30 & 2 \\
\hline Total & 5 & 65 \\
\hline
\end{tabular}

In about two-thirds of the patients this could be measured in years rather than in months or weeks, and this in a relatively young population seems surprising. Perhaps tuberculosis in childhood is not always taken to be a serious disease, and most of it heals by itself. There are, however, a number of cases when sanatorium treatment will save the child with progressive disease. In order to make a correct assessment we must try to observe the history over some years.

Table III shows the classification as to the extent of the disease. It is based on sputum and radiological findings.

It is useful to compare the resected lung specimens with the pre-operative radiographs. I have grouped them into four different stages (Table IV), all of which have the element of fibrosis in common. But it is not always easy to place a specimen into one of these four categories, as it will often be found that parts of the specimen are completely fibrotic, and others
TABLE III

EXTENT OF DISEASE IN CASES $1-100$

\begin{tabular}{|c|c|c|c|c|c|c|c|c|}
\hline $\begin{array}{l}\text { Age } \\
\text { (yr.) }\end{array}$ & $\begin{array}{c}\text { Non- } \\
\text { tuberculous }\end{array}$ & $\mathbf{A}_{1}$ & $A_{2}$ & $\mathbf{B}_{1}$ & $\mathbf{B}_{2}$ & $\mathbf{B}_{3}$ & Total & $\begin{array}{c}\text { Age } \\
\text { (yr.) }\end{array}$ \\
\hline $\begin{array}{r}0-10 \\
11-20 \\
21-30 \\
31-40 \\
41-50 \\
50+\end{array}$ & $\begin{array}{l}2 \\
4 \\
1 \\
1 \\
2\end{array}$ & $\begin{array}{l}1 \\
3 \\
2\end{array}$ & $\begin{array}{l}2 \\
1 \\
1\end{array}$ & $\begin{array}{l}3 \\
7 \\
5 \\
4 \\
2 \\
1\end{array}$ & $\begin{array}{r}2 \\
21 \\
13 \\
7 \\
7 \\
1\end{array}$ & $\begin{array}{l}1 \\
2 \\
3\end{array}$ & $\begin{array}{r}99 \\
39 \\
25 \\
13 \\
10 \\
4\end{array}$ & $\begin{array}{l}0-10 \\
11-20 \\
21-30 \\
31-40 \\
41-50 \\
50+\end{array}$ \\
\hline Total & 10 & 6 & 4 & 22 & 51 & 7 & 100 & Total \\
\hline
\end{tabular}

caseous and/or cavernous, or healed areas are next to fairly active disease. In this situation the specimen has been labelled according to the most active portion.

As can be seen from Table IV, most of the specimens were either caseous or cavernous, but 11 of them had undergone complete fibrosis and were probably quite harmless apart from possible mechanical obstruction during periods of increased secretion, e.g., in colds. All the same, one should not overlook the fact that 80 out of 90 tuberculous specimens had been sputum-positive at the onset of treatment, and the grinding up of an entire specimen for the exclusion of tubercle bacilli was not attempted, though this would have been more thorough a test of sterility. A carnified, airless, and functionless lobe is often a hindrance to proper breathing, and its removal improves lung function. If we try to correlate classification and type of disease, we find in our first 100 cases these results.

Of 10 sputum-negative cases, two were group A, two group $\mathrm{B}$, three group $\mathrm{C}$, and three group D, which is a fairly even distribution. In the early part of the series none of these sputum-negative

TABLE IV

TYPE OF DISEASE IN CASES 1-100

\begin{tabular}{|c|c|c|c|c|}
\hline \multicolumn{4}{|c|}{ Tuberculous } & Non-tuberculous \\
\hline Fibrosis & \begin{tabular}{|c} 
Fibrosis + \\
Bron- \\
chiectasis
\end{tabular} & $\begin{array}{l}\text { Fibro- } \\
\text { caseous }\end{array}$ & $\begin{array}{c}\text { Fibro- } \\
\text { cavernous }\end{array}$ & \multirow{2}{*}{$10\left\{\begin{array}{l}5 \text { bronchiectasis } \\
2 \text { lung cancer } \\
1 \text { lung abscess } \\
1 \text { congenital cystic } \\
\text { disease } \\
1 \text { colloid adenoma }\end{array}\right.$} \\
\hline (A) & (B) & $\begin{array}{l}\text { (C) } \\
33\end{array}$ & (D) & \\
\hline
\end{tabular}

patients had their resected lesions examined for bacilli. We only have reports on the histopathology of the lesions, as cited above. It is also known from experience that a caseous focus or a cavity may no longer contain any tubercle bacilli, whereas a fibrotic lesion sometimes does. Sputum results are therefore misleading, for the lesion may be walled off. We shall come back to this later on. 
Of 80 sputum-positive cases, nine were group $\mathrm{A}$, five group B, 30 group $C$, and 36 group D. No comparable figures are available for bacilli in specimens. All one can say is that only nine of the 80 patients sputum-positive on admission had apparently healed lesions at the time of their operation, whereas in 66 there was still caseation or cavitation present in portions of the resected material.

In order to overcome the above shortcomings, I have included in this review some 47 lung specimens which have been fully examined as the series proceeded (Table V).

Of these 47 cases, 34 were positive for tubercle bacilli, and 13 were negative on direct examination; nine were positive and 38 negative on culture. All but one of these nine culture-positive specimens had also been positive on direct examination. Furthermore, two had never been sputum-positive, and another six patients had become sputum-negative before admission. Of 47 patients, only four had been sputum-positive at the time of operation, and all but two were sputum-negative on discharge. Or, briefly, if one were to judge by sputum results alone, all that operations have achieved in these 47 patients is to reduce the number of sputum-positive cases from four immediately before operation to two at the time of discharge. Together with the results obtained from the examination of the specimens for tubercle bacilli, which were mostly negative on culture, this supports the current opinion that resections for pulmonary tuberculosis are justified only in exceptional cases, and one may even revert to the older view of thoracoplasties in residual cavities, which, after all, are the most likely lesions to flare up, if not collapsed, and long-term results of modern forms of thoracoplasty have stood the test of time.

TABLE V

FINDINGS IN 47 CASES OF LUNG RESECTION

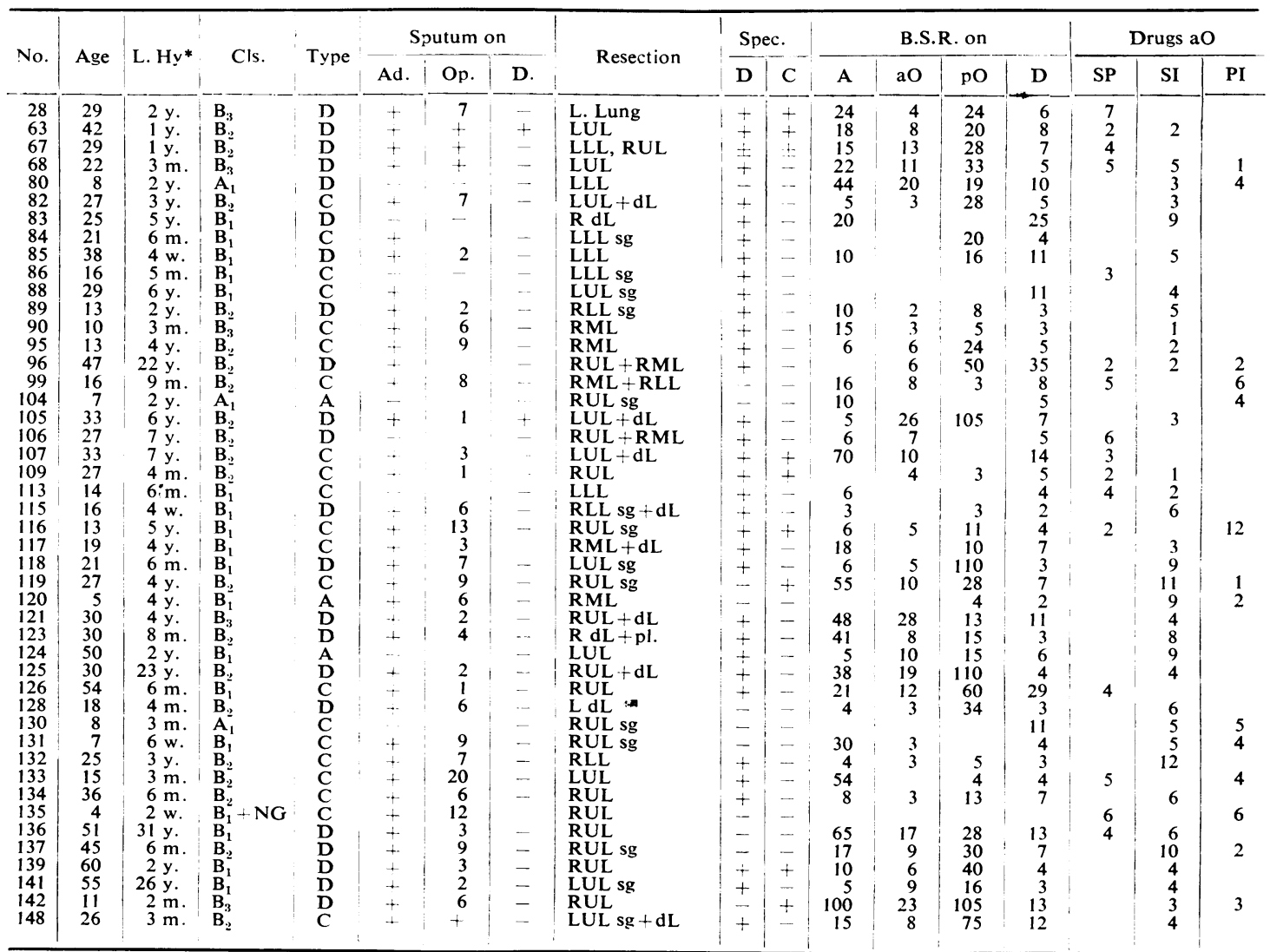


Table $\mathrm{V}$ gives relevant details about these 47 operations as to serial number (No.), age, length of history (L.Hy), classification (Cls.), type of disease (Type) (cf. also Table IV), sputum on admission, at the time of operation, and on discharge (Sputum on Ad., Op., D.), the part resected (Resection), examination of the operation specimen for tubercle bacilli on direct and on culture test (Spec. D, C), the stabilitary reaction of the blood on admission, before and after operation, and on discharge ( $\mathrm{BSR}$ on $\mathrm{A}, \mathrm{aO}, \mathrm{pO}, \mathrm{D}$ ), and finally the pre-operative drug treatment in months of the combinations streptomycin and P.A.S. (SP), streptomycin and I.N.A.H. (SI), and P.A.S. and I.N.A.H. (PI).

All but one of the 47 patients (No. 84) had pre-operative drug treatment lasting from one to 14 months. Two of the specimen-culture positive patients (Nos. 116 and 119) had pre-operative antibiotic treatment for more than one year. It is now generally accepted that one may still find positive cultures even after 18 months of drug therapy, but on the average six months of preoperative drug treatment will suffice to render a patient's culture negative.

Table VI correlates the 35 resected specimens with demonstrable tubercle bacilli (direct and/or on culture) with the last positive sputum before operation.

TABLE VI

SPUTUM FINDINGS IN 35 PATIENTS WITH DEMONSTRABLE TUBERCLE BACILLI (DIRECT AND'OR ON CULTURE) IN RESECTED LUNG SPECIMENS

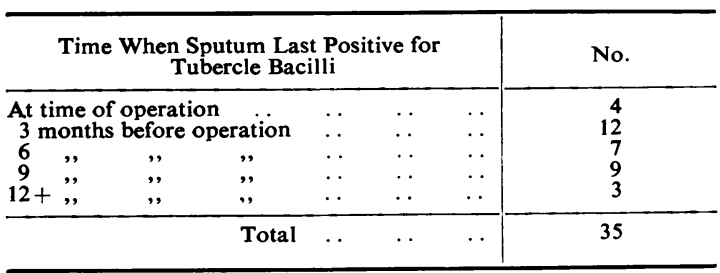

Here again the figures indicate that it pays to wait six to nine months before deciding on an operation, and to treat strictly on sanatorium

TABLE VII

TYPE OF SURGERY IN CASES $1-100$

\begin{tabular}{|c|c|c|c|c|c|c|c|c|c|}
\hline Age (yr.) & $0-10$ & $11-20$ & $21-30$ & $31-40$ & $41-50$ & $50+$ & & & Total \\
\hline 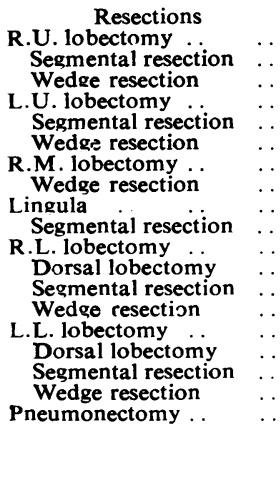 & $\begin{array}{l}3 \\
3 \\
2\end{array}$ & $\begin{array}{r}9 \\
2 \\
11 \\
3 \\
3 \\
1 \\
2 \\
3 \\
2 \\
3 \\
1 \\
6 \\
3 \\
1 \\
4\end{array}$ & $\begin{array}{r}7 \\
5 \\
3 \\
1 \\
12 \\
1 \\
1 \\
1\end{array}$ & $\begin{array}{l}4 \\
3 \\
1 \\
2\end{array}$ & $\begin{array}{l}4 \\
4 \\
2 \\
4 \\
\\
1\end{array}$ & $\begin{array}{l}1 \\
1\end{array}$ & $\begin{array}{l}\text { RUL } \\
\text { LUL } \\
\text { RML } \\
\text { Lingula } \\
\text { RLL } \\
\text { LLL } \\
\quad 4 \ldots\end{array}$ & $\begin{array}{r}25 \\
15 \\
8 \\
6 \\
5 \\
10 \\
69 .\end{array}$ & 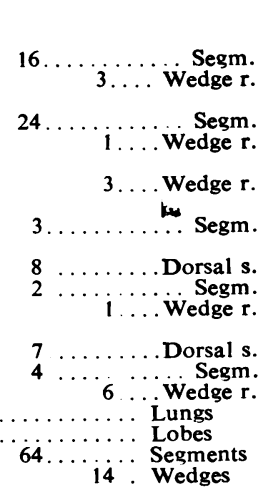 \\
\hline Operative weight loss & $0-6$ & $0-18$ & $0-14$ & $0-16$ & $0-18$ & & & & \\
\hline Average (lb.) .. & 2 & $6 \frac{1}{2}$ & $5 \frac{1}{2}$ & 8 & 8 & $5 \frac{1}{2}$ & & & \\
\hline $\begin{array}{l}\text { Days in hospital: } \\
\text { Before operation } \\
\text { After , } \\
\text { Total (averäg) } \\
\end{array}$ & $\begin{array}{l}410 \\
216 \\
626\end{array}$ & $\begin{array}{l}291 \\
232 \\
523\end{array}$ & $\begin{array}{l}160 \\
181 \\
341\end{array}$ & $\begin{array}{l}132 \\
187 \\
319\end{array}$ & $\begin{array}{l}106 \\
171 \\
277\end{array}$ & $\begin{array}{l}15 \\
51 \\
66\end{array}$ & & & \\
\hline $\begin{array}{c}\text { Pre-operative treatment: } \\
\text { Posture } \\
\text { Phrenic crush ... } \\
\text { Pneumoperitoneum .. } \\
\text { Artificial pneumothorax } \\
\text { Thoracoplasty .. }\end{array}$ & $\begin{array}{l}2 \\
1 \\
1\end{array}$ & $\begin{array}{r}10 \\
1 \\
5 \\
4\end{array}$ & $\begin{array}{r}10 \\
4 \\
6 \\
6\end{array}$ & $\begin{array}{l}2 \\
1 \\
2 \\
3 \\
1\end{array}$ & $\begin{array}{l}1 \\
2\end{array}$ & & & $\begin{array}{r}27 \\
3 \\
12 \\
14 \\
9\end{array}$ & \\
\hline $\begin{array}{l}\text { Post-operative treatment } \\
\text { Posture } \\
\text { Phrenic crush } \ldots\end{array}$ & $\begin{array}{l}1 \\
3\end{array}$ & $\begin{array}{r}1 \\
18 \\
8\end{array}$ & $\begin{array}{r}5 \\
12\end{array}$ & $\begin{array}{l}1 \\
4\end{array}$ & 8 & 1 & & $\begin{array}{r}2 \\
27 \\
33\end{array}$ & \\
\hline
\end{tabular}


lines with, or even without, drugs, for the number of patients requiring operation falls as drug therapy continues.

It follows from Table $\mathrm{V}$ that it is apparently unnecessary to examine large numbers of specimens in order to get some working rule, as the general trend of medical treatment becomes apparent after only a few tests. All the same, it is a better routine to examine the specimen in each individual case, as this will help in deciding on the length of post-operative drug treatment, and also on the prognosis.

To return to the review of the first 100 cases, Table VII contains a brief summary of some interesting data which are self-explanatory. Special mention should be made once more of the corrective procedures following resection operations, e.g., phrenic crush and thoracoplasty. Selection here depends very much on the age of the patient.

Table VIII deals with the pre- and postoperative drug treatment in hospital. As a rule, antibiotic medication is recommended on dis-

TABLE VIII

DRUG TREATMENT IN HOSPITAL

\begin{tabular}{c|c|c}
\hline $\begin{array}{c}\text { Duration } \\
\text { (mth.) }\end{array}$ & $\begin{array}{c}\text { (Streptomycin +P.A.S.) or } \\
\text { (Streptomycin +I.N.A.H.) or (P.A.S. + I.N.A.H.) }\end{array}$ \\
\cline { 2 - 3 } & Pre-operative & $\begin{array}{c}\text { Post-operative } \\
\text { until Discharge }\end{array}$ \\
\hline $1-3$ & 21 & 39 \\
$4-6$ & 38 & 32 \\
$7-9$ & 10 & 7 \\
$10-12$ & 6 & 4 \\
$12+$ & 4 & 1 \\
\hline Total & 79 & 83 \\
\hline
\end{tabular}

charge, to be continued at home. It usually refers to P.A.S. and I.N.A.H. only. Once this regimen is attained, the patient will normally be ready for transfer or discharge home for final convalescence.

Only 79 of the first 100 patients received preoperative drug therapy. After deduction of the 10 non-tuberculous cases, the remaining 11 patients presented as follows: Four had localized primary tuberculous lesions. Two were intolerant of drugs. One underwent an exploration for diagnosis of a suspected lung abscess, later proved tuberculous. One had an operation for old tuberculosis after a spontaneous pneumothorax. Three were admitted for resection of tuberculomas without preliminary drug therapy. In these patients operation could be performed at once or after a short period of rest, as one could reasonably expect a high probability of radical cure. This policy aimed at cutting down the time the patient would have to spend in hospital.

Failures of drug treatment on discharge from hospital numbered three streptomycin-resistant, four drug-intolerant, and four sputum-positive patients, also a total of 11 . These pitfalls of medical treatment must be considered when surgery is contemplated.

Sputum tests cannot be relied upon to pronounce a lesion as being sterile. Patients become sputum-negative long before the disappearance of tubercle bacilli from their lesions. It is therefore advisable to support one's clinical judgment by monthly blood stabilitary reaction tests. Westergren's method was used. It is more accurate to take readings of a test at two intervals and thereby study the progression of the sedimentation reaction. Our figures were obtained by comparing the reading for the first hour with half the one for the second hour. The higher of these two figures gives the final sedimentation value in millimetres per hour.

TABLE IX

STABILITARY REACTION OF BLOOD (B.S.R.) IN MM. PER HOUR (200 MM. WESTERGREN) RELATED TO SPUTUM RESULTS IN 50 PATIENTS

\begin{tabular}{|c|c|c|c|c|}
\hline \multicolumn{2}{|l|}{$\begin{array}{c}\text { On } \\
\text { Admission }\end{array}$} & $\begin{array}{l}\text { Before or } \\
\text { at Operation }\end{array}$ & \multirow[t]{3}{*}{$\begin{array}{c}\text { After } \\
\text { Operation }\end{array}$} & \multirow{3}{*}{$\begin{array}{c}\begin{array}{c}\text { On } \\
\text { Discharge }\end{array} \\
46 \\
4 \\
4\end{array}$} \\
\hline $\begin{array}{l}\text { Sputum negative } \\
\text { Sputum last positive } \\
\text { operation (mth.) }\end{array}$ & $\begin{array}{r}13 \ldots \\
\text { e before } \\
. .\end{array}$ & \begin{tabular}{c|r|}
13 & + \\
$(1-3)$ & 29 \\
$(4-6)$ & 9 \\
$(7-9)$ & 9 \\
$(9+)$ & 5 \\
\end{tabular} & & \\
\hline Sputum positive & 37 & $\overline{8}$ & & \\
\hline Total & 50 & 50 & & 50 \\
\hline $\begin{array}{l}\text { B.S.R. in mm.: } \\
1-3 \text { (normal) } \\
4-10 \text { (doubtful) }\end{array}$ & $1\} 18$ & ${ }^{8}, 36$ & & $11) 40$ \\
\hline $\begin{array}{l}11-20 \\
21-30 \\
31-40 \text { (raised) } \\
41-50 \\
50+\end{array}$ & $\left.\begin{array}{r}17 \\
13 \\
9 \\
3 \\
3 \\
4\end{array}\right\} 32$ & \begin{tabular}{r|r|r|}
28 & \\
9 & \\
4 & & \\
& 14 &
\end{tabular} & $\left.\begin{array}{r}10 \\
15 \\
12 \\
5 \\
2 \\
5\end{array}\right\} 39$ & $\begin{array}{r}29) \\
7 \\
2\end{array} \int_{-10}$ \\
\hline Total & 50 & 50 & 50 & 50 \\
\hline
\end{tabular}

In the follow-up of a case (Table IX) an acute phase, a surgical interval, and finally a healing phase can be distinguished.

In the recovery period the figure for the first hour returns to normal much sooner than the one for the second hour. When the condition has become stable the ratios of the first and of the second hour are approximately equal, as they are 
in normally healthy people. It appears advisable to postpone the operation until the B.S.R. shows a tendency to come down in successive tests (cf. Table V).

Table IX illustrates well the relationship between sputum results and B.S.R., as measured on admission, before or at and after operation, and on discharge. It shows that of 50 patients, 37 had positive sputum on admission with the largest numbers in the $4-10 \mathrm{~mm}$. (17) and $11-20 \mathrm{~mm}$. (13) B.S.R. groups. At the time of operation only 18 sputum-positive cases remained and most of the B.S.R. values fall into the $4-10 \mathrm{~mm}$. group. Finally, on discharge the four sputum-positive cases are well represented in the few remaining numbers (3) of B.S.R. values above $20 \mathrm{~mm}$. It must, however, be emphasized that every patient should be judged on his individual merits (cf. Table V) when this correlation can be studied.

It seems to follow from individual as well as from statistical observations that the majority of patients have entered the healing phase when they come on the operating table to have residual lesions excised.

\section{RESULTS}

The first 100 patients (1952-6) have been followed up after their discharge from hospital. They have fared as follows:

One was not available, and five had died (one of neoplasm and four of pulmonary tuberculosis). The four pulmonary tuberculosis deaths were caused by one post-operative haemorrhage 30 minutes after closure of the chest ; one postoperative pulmonary oedema following 15 days after operation which had been complicated by haemothorax; and two broncho-pleural fistulas, each two years after operation.

For the remaining 94 patients results have been obtained from their respective chest clinics (Table X).

The minimum follow-up time after operation has been three years (Nos. 1-100). The series comprises some 200 patients. There have been two deaths in the later series, one on the seventeenth post-operative day from pulmonary oedema (No. 146) after a pneumonectomy for
TABLE X

FOLLOW-UP RESULTS OF 94 PATIENTS UNDERGOING 100 RESECTIONS AFTER THREE TO SEVEN YEARS (1959)

\begin{tabular}{llll|c}
\hline Poor & $\ldots$ & $\ldots$ & $\ldots$ & 1 (severe bronchitis) \\
Fair & $\ldots$ & $\ldots$ & $\ldots$ & 3 (cough with sputum) \\
Good & $\ldots$ & $\ldots$ & $\ldots$ & 20 (persistently good) \\
\hline
\end{tabular}

neoplasm, and the other (No. 154) on the third post-operative day after a corrective thoracoplasty following a resection some 49 days previously. Death was apparently due to failure of liver function. (It appears advisable to carry out routine tests at regular intervals on all patients undergoing prolonged antibiotic therapy.) Latterly, almost all the resections have been for bronchial neoplasm, which has become a major surgical disease.

\section{SUMMARY}

When are lung resections really necessary? This question has been examined in a series of 100 patients (Nos. 1-100), of whom 90 had been suffering from pulmonary tuberculosis and 10 from other chest diseases. The operations were performed between 1952 and 1956 and the patients were followed up for at least three years. Only about $8 \%$ of some 1,300 patients, resident at the time, had resections. Forty-seven lung resection specimens were examined not only histologically but also to some extent bacteriologically. Some conclusions were drawn from these observations which seem to confirm the current state of guarded optimism regarding medical treatment of pulmonary tuberculosis. The number of patients with tuberculosis who will eventually require a resection is steadily declining. Serial examinations of the stabilitary reaction of blood should be done more consistently not only in hospitals but also in chest clinics. It is becoming increasingly difficult to write a paper on resection operations as time goes by. Adequate medical treatment of early recognized lesions has become a matter of routine. Surgery has remained tantamount in carcinoma of the lung, which now occupies our attention.

Thanks are extended to Mr. Ifor Lewis, surgeon, Dr. John B. Morrison, medical superintendent, and the staff of Abergele Chest Hospital for their patient co-operation in this study. 